\title{
Caracterización molecular del segmento 4 del virus de la tilapia de lago aislado de tilapias (Oreochromis niloticus) cultivadas en Perú
}

\author{
Molecular characterization of segment 4 of lake tilapia viruses isolated from \\ tilapia (Oreochromis niloticus) farmed in Peru
}

\author{
Shirley Palacios H. ${ }^{1}$, Alberto Manchego S. ${ }^{2}$, Gina Castro S. ${ }^{1}$, Antonio Herrera R. ${ }^{1}$, \\ Adhemir Valera A. ${ }^{1}$, Nieves Sandoval C. ${ }^{1,3}$
}

\section{Resumen}

El objetivo del presente estudio fue la caracterización molecular del segmento 4 del virus de la tilapia de lago (TiLV) detectado en tilapias de cultivo de los departamentos de Piura (Costa) y San Martín (Selva) en un brote ocurrido en 2017-2018. En el brote se obtuvo 26 muestras positivas a TiLV, de las cuales se seleccionaron cinco muestras positivas. El diagnóstico de estas muestras se realizó a través de un RT-PCR anidada con cebadores dirigidos al segmento 3 y los productos de PCR fueron secuenciados. Para la amplificación y análisis del segmento 4 del genoma del TiLV se realizó un RT-PCR donde se diseñaron cebadores específicos. La secuenciación se hizo con la empresa Macrogen (Corea del Sur), mediante secuenciación bidireccional por el método de Sanger automatizado. El análisis filogenético se realizó a partir de las secuencias alineadas por medio del método de Neighbor-Joining (NJ) y la característica de la proteína hipotética del gen se realizó con el programa Phyre2. Se obtuvieron cuatro secuencias completas del segmento 4 (1 de Piura y 3 de San Martín) con una longitud de 1190 pb siendo comparadas con dos secuencias de Israel y una de Tailandia, cepas referenciales correspondientes al segmento 4 de TILV publicadas GeneBank. El análisis filogenético del segmento 4 determinó la presencia de un genogrupo TiLV local, además de indicar que las muestras peruanas presentan mayor relación genética con el clado de cepas de

\footnotetext{
${ }^{1}$ Laboratorio de Histología, Embriología y Patología Veterinaria, Facultad de Medicina Veterinaria, Universidad Nacional Mayor de San Marcos, Lima, Perú

${ }^{2}$ Laboratorio de Microbiología y Parasitología Veterinaria, Facultad de Medicina Veterinaria, Universidad Nacional Mayor de San Marcos, Lima, Perú

${ }^{3}$ Email: nsandovalc@unmsm.edu.pe
}

Recibido: 5 de julio de 2020

Aceptado para publicación: 20 de febrero de 2021

Publicado: 24 de abril de 2021 
Israel. El análisis de distancia genética muestra que las muestras peruanas mostraron valores de identidad nucleotídica de $99.7-100 \%$ entre ellas, determinando que los brotes de ambos lugares fueron producidos por la misma cepa viral, y tienen una identidad de 97.5-97.7\% con cepas de Israel y 97.0-97.1\% con cepas de Tailandia. Se determinó que la proteína hipotética a partir del segmento 4 del TiLV tiene una región con una homología estructural con la proteína neuraminidasa N6 del pato inglés con $12 \%$ de cobertura, $44 \%$ de identidad y $24.9 \%$ de confianza.

Palabras clave: tilapias, TiLV, segmento 4, RT-PCR, análisis filogenético

\section{ABSTRACT}

The aim of this study was the molecular characterization of segment 4 of the lake tilapia virus (TiLV) detected in farmed tilapia from the departments of Piura (Coast) and San Martín (Jungle) in an outbreak that occurred in 2017-2018. During this outbreak, 26 TiLV positive samples were obtained and five of them were selected. The diagnosis of these samples was carried out through a nested RT-PCR with primers directed to segment 3 and the PCR products were sequenced. For the amplification and analysis of segment 4 of the TiLV genome, an RT-PCR was performed where specific primers were designed. The sequencing was done by Macrogen (South Korea), by bidirectional sequencing using the automated Sanger method. The phylogenetic analysis was carried out from the aligned sequences by means of the Neighbor-Joining (NJ) method and the hypothetical protein characteristics of the gene was carried out with the Phyre2 program. Four sequences with a length of $1190 \mathrm{bp}$ were obtained and compared with two sequences from Israel and one from Thailand, reference strains corresponding to segment 4 of TILV published GenBank. The phylogenetic analysis of segment 4 determined the presence of a local TiLV genogroup, in addition to indicating that the Peruvian samples have a greater genetic relationship with the clade of Israel strains. The genetic distance analysis shows that the Peruvian samples have nucleotide identity values of $99.7-100 \%$ between them, determining that the outbreaks of both locations were produced by the same viral strain, and have an identity of $97.5-97.7 \%$ with strains from Israel and $97.0-97.1 \%$ with strains from Thailand. The hypothetical protein from TiLV segment 4 was determined to have structural homology to the neuraminidase N6 protein from English duck influenza A virus with $12 \%$ coverage, $44 \%$ identity, and $24.9 \%$ confidence.

Key words: tilapia, TiLV, segment 4, RT-PCR, phylogenetic analysis

\section{INTRODUCCIÓN}

La tilapia es una rica fuente de proteínas y micronutrientes de alta calidad, por lo que su consumo se ha incrementado a nivel global (FAO, 2018). En el Perú, el cultivo de tilapias presenta grandes perspectivas de desarrollo, siendo los departamentos de San Martín y Piura los que presentan el mayor potencial para el desarrollo óptimo del cultivo de tilapias (PRODUCE 2017). De esta manera, la tilapia es el segundo pez más cultivado en el país (PRODUCE, 2017). Sin embargo, la intensificación de su producción puede causar estrés en los peces, haciéndolos susceptibles a diversos agentes infecciosos, entre ellos, los virus (Dong et al., 2017a; Surachetpong et al., 2017; Amal et al., 2018; Behera et al., 2018). 
Se ha identificado un nuevo virus que afecta a la tilapia cultivada y silvestre, denominado virus de la tilapia de lago (TiLV) (Eyngor et al., 2014, Ferguson et al., 2014; Bacharach et al., 2016; Del Pozo et al., 2017). Este virus causa una mortalidad y morbilidad cercana al $90 \%$ en alevines y $9 \%$ en juveniles y adultos (Eyngor et al., 2014; Bacharach et al., 2016), representando un grave riesgo para la crianza de tilapia (OIE, 2018a). El virus del TiLV ha sido notificado en 13 países de África, Asia y América del sur (Jansen et al., 2018); sin embargo, ante la ausencia de investigaciones exhaustivas sobre todos los incidentes de mortalidad, es posible que la distribución geográfica de TiLV sea más amplia que la conocida actualmente (OIE, 2018a).

El TiLV se describió como un nuevo virus de la familia Orthomyxoviridae (Eyngor et al., 2014); sin embargo, debido a que TiLV no está directamente relacionado con alguno de los ortomixovirus actualmente clasificados, el Comité Internacional de Taxonomía de Virus determinó clasificarlo dentro de un nuevo género denominado Tilapinevirus y como especie Tilapia tilapinevirus, indicando que se deberían realizar más estudios antes de que este género pueda ser incluido como un Ortomixovirus (Adams et al., 2017).

Este virus posee un genoma ARN de 10 segmentos de sentido negativo que presentan secuencias terminales 5' y 3' homólogas (Bacharach et al., 2016). El segmento 1 posee una homología de secuencia con la subunidad de la proteína básica 1 (PB1) de la ARN polimerasa dependiente de ARN del virus influenza C (Bacharach et al., 2016), mientras los otros nueve segmentos no mostraron homología con otros virus, pero tienen secuencias conservadas y complementarias en sus extremos $5^{\prime}$ y $3^{\prime}$, de acuerdo con la organización del genoma que se encuentra en otros ortomixovirus (Barachach et al., 2016). Los ortomixovirus tienen sus proteínas inmunogénicas y neutralizantes en las proteínas hemaglutinina (HA) y neuroa- minidasa (NA). Las HA desempeñan funciones vitales en la entrada del virus al unirse al ácido siálico en las superficies de las células epiteliales, lo que promueve la fusión de la envoltura con la membrana celular. Por otro lado, NA escinde el ácido siálico en las proteínas del virión para evitar la acumulación y facilita la liberación de virus de las células infectadas (Wagner et al., 2002). En el virus de la influenza (prototipo de la familia), la HA está codificado en el segmento 4 y NA en el segmento 6, mientras en los Isavirus (anemia infecciosa del salmón), la HA está codificada en el segmento 6 y el segmento 4 codifica la polimerasa ácida putativa (PA) (Plarre et al., 2012).

En el Perú se ha detectado su presencia (OIE, 2018b; SANIPES, 2018), siendo necesario realizar un estudio de la caracterización molecular del virus, en especial en los segmentos que codifican las proteínas inmunogénicas HA y NA, a fin de poder establecer métodos preventivos, como la elaboración de vacunas que contengan estas variantes génicas que las hagan inmunológicamente eficientes. El presente estudio tuvo como objetivo la caracterización molecular del segmento 4 del TiLV y así poder determinar la posible función de la proteína hipotética obtenida a partir de la secuencia de dicho segmento de las muestras positivas obtenidas de las regiones con mayor producción de tilapias en el Perú.

\section{Materiales y Métodos}

\section{Lugar de Estudio y Muestras}

Se seleccionaron al azar cinco muestras positivas a TiLV de un total de 26 muestras positivas que fueron obtenidas durante el brote registrado por primera vez en el Perú entre diciembre de 2017 (Piura) y junio de 2018 (San Martín). Las muestras provinieron de tilapias de cultivo de los dos departamentos mencionados (Cuadro 1). El estudio 
Cuadro 1. Identificación y origen de las muestras utilizadas en la secuenciación del segmento 4 del TiLV

\begin{tabular}{ccc}
\hline Id muestra & Origen & Año \\
\hline TILV Perú T04 & Piura & 2017 \\
TILV Perú T07 & Piura & 2017 \\
TILV Perú T18 & San Martín & 2018 \\
TILV Perú T24 & San Martín & 2018 \\
TILV Perú T28 & San Martín & 2018 \\
\hline
\end{tabular}

molecular se desarrolló en el Laboratorio de Ictiopatología de la Facultad de Medicina Veterinaria de la Universidad Nacional Mayor de San Marcos, Lima.

Se tomaron muestras de riñón anterior, hígado, cerebro y líquido intraocular, los cuales fueron homogenizados en solución salina ( $\mathrm{NaCl} 0.9 \%)$ hasta lograr una suspensión del $20 \%$. Se transfirió $1 \mathrm{ml}$ del homogenizado a un microtubo de $2 \mathrm{ml}$ y se conservó a $-80{ }^{\circ} \mathrm{C}$ hasta la extracción de ARN y caracterización molecular del segmento 4. El diagnóstico a TiLV fue determinado a través de un RT-PCR anidada con cebadores dirigidos al segmento 3 según lo descrito por Tsofack et al. (2017) y los productos de PCR fueron secuenciados.

\section{Extracción de ARN y Síntesis de ADNc}

La extracción del ARN total se obtuvo tomando $300 \mu 1$ de cada muestra homogeneizada a la cual se agregó $1 \mathrm{ml}$ de reactivo TRIzol LS (Thermo Scientific, USA), siguiendo las instrucciones del fabricante. El ARN total purificado se almacenó a $-80^{\circ} \mathrm{C}$.

Las muestras purificadas de ARN total fueron sometidas a retrotranscripción para la generación de ADN complementario (ADNc) (GoScript TM; Promega, USA) uti- lizando cebadores específico-externos previamente descritos: Ext-1 y Ext-2 (Cuadro 2). Se realizó una etapa previa de desnaturalización donde se incubó $5 \mu 1$ de muestras de ARN a $97{ }^{\circ} \mathrm{C}$ durante $5 \mathrm{~min}$ y se mantuvo a $4{ }^{\circ} \mathrm{C}$.

La mezcla de reacción de retrotranscripción se preparó para un volumen final de $10 \mu 1$ por muestra, acorde a las siguientes proporciones: $2.00 \mu 1$ de GoScriptTM 5X Reaction Buffer, $1.20 \mu 1 \mathrm{MgCl}_{2}(25 \mathrm{mM}), 0.50 \mu 1 \mathrm{dNTP}$ $(10 \mathrm{mM}), 0.25 \mu 1$ de los cebadores externos Ext-1 $(20 \mu \mathrm{M})$ y Ext-2 $(20 \mu \mathrm{M}), 0.40 \mu \mathrm{de}$ GoScriptTM Reverse Transcriptase, $0.40 \mu 1$ de agua libre de nucleasas y, finalmente, se adicionó los $5 \mu 1$ del ARN desnaturalizado. Se usaron las siguientes condiciones de temperatura: $25^{\circ} \mathrm{C}$ durante $5 \mathrm{~min}, 42^{\circ} \mathrm{C}$ durante 45 min y se mantuvo a $4{ }^{\circ} \mathrm{C}$. El ADNc final se almacenó a $-20^{\circ} \mathrm{C}$ hasta su uso en PCR.

\section{Amplificación del Segmento 3 del TiLV}

El diagnóstico del TiLV se llevó a cabo mediante la prueba de RT- PCR anidada, utilizando el kit GoTaq ${ }^{\circledR}$ G2 Green Master Mix (Promega, USA). Se utilizaron los cebadores descritos por Tsofack (2017) para la detección del segmento 3 del genoma de TiLV.

Se preparó la mezcla de reacción de PCR (primera ronda y anidada) en un volumen final de $25 \mu 1$. La primera PCR amplificó un fragmento de $491 \mathrm{pb}$ del segmento 3 del genoma de TiLV (PCR externa) usando $12.5 \mu 1$ de $2 x$ Master mix, $0.25 \mu 1$ de los cebadores externos (Ext1 y Ext2) (Cuadro 2), $5 \mu 1$ de cDNA y $7 \mu 1$ de agua libre de nucleasas. Las condiciones de PCR fueron: $94{ }^{\circ} \mathrm{C}$ durante 3 min seguidos de 30 ciclos de $94{ }^{\circ} \mathrm{C}$ durante $30 \mathrm{~s}$ (desnaturalización), $54{ }^{\circ} \mathrm{C}$ durante $60 \mathrm{~s}$ (hibridación) y $72{ }^{\circ} \mathrm{C}$ durante $60 \mathrm{~s}$ (extensión), y un paso de extensión final de $72{ }^{\circ} \mathrm{C}$ durante $5 \mathrm{~min}$. Los productos amplificados fueron utilizados para un segundo PCR (PCR anidada), en el cual se emplearon los cebadores ME1 y ME2 (Cuadro 2), amplificando un fragmento de $250 \mathrm{pb}$. La mezcla de PCR se preparó usando $12.5 \mu 1$ de $2 x$ Master 
Cuadro 2. Cebadores específicos utilizados para el diagnóstico del virus de la tilapia de lago (TiLV) por RT-PCR anidada. Los cebadores amplifican secuencias específicas del segmento 3 del genoma de TiLV

\begin{tabular}{lccl}
\hline Cebadores & Secuencia $\left(5^{\prime}-3^{\prime}\right)$ & $\begin{array}{c}\text { Tamaño } \\
(\mathrm{pb})\end{array}$ & Referencias \\
\hline Ext1 & TATGCAGTACTTTCCCTGCY & \multirow{2}{*}{491} & Eyngor et al., 2014 \\
Ext2 & TTGCTCTGAGCAAGAGTACC & & $\begin{array}{l}\text { Tsofack } \text { et al., } 2017 \\
\text { ME1 }\end{array}$ \\
GETGGGCACAAGGCATCCTA & \multirow{2}{*}{250} & Dong et al., 2017 \\
\hline
\end{tabular}

mix, $0.25 \mu 1$ de cebador ME1 $(20 \mu \mathrm{M})$ y ME2 $(20 \mu \mathrm{M}), 9 \mu \mathrm{l}$ de agua libre de nucleasas y $3 \mu \mathrm{l}$ del producto de PCR de la primera ronda. Las condiciones fueron: $94^{\circ} \mathrm{C}$ durante $3 \mathrm{~min}$, seguidos de 30 ciclos de $94{ }^{\circ} \mathrm{C}$ durante $30 \mathrm{~s}$, $60{ }^{\circ} \mathrm{C}$ durante $60 \mathrm{~s}$ y $72{ }^{\circ} \mathrm{C}$ durante $60 \mathrm{~s}$, y un paso de extensión final de $72{ }^{\circ} \mathrm{C}$ durante $5 \mathrm{~min}$.

Los productos de PCR fueron revelados mediante electroforesis en gel de agarosa al $1.5 \%$ en solución tampón TBE (Tris/ Borate/EDTA) 0.5X, utilizando bromuro de etidio, visualizados a través de un transiluminador UV y utilizando marcadores de peso molecular de Promega, USA (100 pb DNA Ladder). Cinco de las muestras positivas fueron utilizadas para la caracterización del segmento 4 del TiLV.

\section{Amplificación del segmento 4 del TiLV}

Para la amplificación y análisis del segmento 4 del genoma de TilV se determinó un tamaño de $1190 \mathrm{pb}$ en el segmento 4, basado en el análisis de la secuencia referencial de la cepa israelí (N. ${ }^{\circ}$ de acceso KU751817.1) disponible en el GeneBank. Para ello, se diseñaron los cebadores específicos que enmarcan la secuencia amplificándola en dos porciones que se empalman. Los cebadores específicos fueron diseñados utilizando el programa PRIMER 3 (Cuadro 3).
Se utilizó el kit comercial GoTaq ${ }^{\circledR}$ Green Master Mix (Promega, USA) siguiendo las instrucciones del fabricante, trabajando en volumen de reacción $25 \mu 1$. La proporción de reactivos fue la siguiente: $12.5 \mu 1$ Green GoTaq ${ }^{\circledR}$ Reaction Buffer 2x, $0.25 \mu 1$ Cebador seg4-1P forward (20 uM), $0.25 \mu 1$ Cebador seg4-1P reverse (20 uM), $5.00 \mu \mathrm{l}$ ADNc y $7.00 \mu 1$ de agua libre de nucleasas.

La mezcla de PCR consistió en $20 \mu \mathrm{M}$ de los cebadores, $7 \mu 1$ de agua, $12.5 \mu 1$ de tampón $2 \mathrm{x}, 5 \mu 1$ de ADNc. La amplificación se realizó en un termociclador TurboCycler 2 (Bio Tech) a través de una desnaturalización inicial a $94{ }^{\circ} \mathrm{C}$ durante $3 \mathrm{~min}, 35$ ciclos a $94{ }^{\circ} \mathrm{C}$ durante $30 \mathrm{~s}, 54{ }^{\circ} \mathrm{C}$ durante $1 \mathrm{~min}, 72{ }^{\circ} \mathrm{C} \mathrm{du}$ rante $1 \mathrm{~min}$, y finalmente una etapa de extensión final de $72{ }^{\circ} \mathrm{C}$ durante $5 \mathrm{~min}$.

Los productos de PCR fueron revelados mediante electroforesis en gel de agarosa al $1.5 \%$ en solución tampón TBE (Tris/ Borate/EDTA) 0.5X, utilizando bromuro de etidio, visualizados a través de un transiluminador UV y utilizando marcadores de peso molecular de Promega, USA (100 bp DNA Ladder). Se utilizó un voltaje de $140 \mathrm{v}$ durante 30 min para observar las bandas en el tamaño esperado del segmento 4 del TiLV. 
Cuadro 3. Cebadores específicos diseñados para la amplificación del segmento 4 del virus de la tilapia de lago (TiLV) aislado en el Perú

\begin{tabular}{cccl}
\hline Segmento & $\begin{array}{c}\text { Tamaño del } \\
\text { producto }(\mathrm{pb})\end{array}$ & Sentido & \multicolumn{1}{c}{ Secuencia (5'-3') } \\
\hline \multirow{2}{*}{ TiLVseg4-1P } & \multirow{2}{*}{724} & Fw & GCAAATCTTTCTCCAATTACCGT \\
& & Rv & GTGTTCGCATTGAGGTCTGG \\
TiLVseg4-2P & \multirow{2}{*}{686} & Fw & GGAGGCGGGATTATAGCAGT \\
& & Rv & ACAAAGACTAGTATGGCAGCTG \\
\hline
\end{tabular}

\section{Secuenciación}

Los productos de PCR fueron enviados a Macrogen Inc (Corea del Sur), donde fueron sometidos a secuenciación bidireccional mediante el método de Sanger automatizado. Para ello, los productos de PCR fueron preparados de acuerdo con las indicaciones de volumen y concentración requeridas por la empresa para la secuenciación del segmento 4 del TiLV. Se colocaron $25 \mu 1$ de los productos obtenidos en tubos de microcentrífuga de $1.5 \mathrm{ml}$ y fueron enviados a temperatura ambiente. Los resultados se recibieron en archivo de software Chromas Lite 2.1.1, donde cada lectura de secuenciación se pudo visualizar en gráficos (cromatogramas).

\section{Análisis de Secuencia de Nucleótidos y Análisis Filogenético}

La edición y empalme de las secuencias obtenidas se realizaron mediante el software Chromas Lite v. 2.1.1 y EditSeq v. 7.0.0 de DNASTAR Lasergene. La alineación de secuencias múltiples se realizó usando el método ClustalW (Thompson et al., 1994) usando el software MegAlign 7.0 de DNASTAR Lasergene (Clewley y Arnold, 1997). La edición se llevó a cabo utilizando tres secuencias como base de comparación, las cepas de referencia de Israel (Accesión
KU751817.1 y KU552133.1) y Tailandia (Accesión KX631924.1) disponibles en Genbank. El análisis genético y porcentaje de identidad genética se realizaron mediante el software MegAlign 7.0 y MEGA 7 (Kumar et al., 2016).

Se construyó el árbol filogenético a partir de las secuencias alineadas por medio del método de Neighbor-Joining (NJ) (Saito y Nei, 1987) utilizando los parámetros del modelo 2 de distancia de Kimura (Kimura, 1980) y boostrap de 1000 réplicas para la determinación del valor de confiabilidad porcentual en cada nodo interno del árbol. De esta esta manera se representan gráficamente las relaciones y patrones de distancia genética entre las cepas del TiLV peruanas y las cepas de referencia disponibles en GeneBank.

\section{Análisis de Estructura y Función de la Proteína Hipotética}

Se utilizó el programa Phyre2 para el modelamiento estructural por enhebramiento de las secuencias de aminoácidos obtenidos en el estudio del segmento 4 del TiLV (Kelley et al., 2015). Para determinar la presencia de regiones transmembrana de la putativa proteína se utilizó el software TMpred (Hofmann y Stoffel, 1993). 


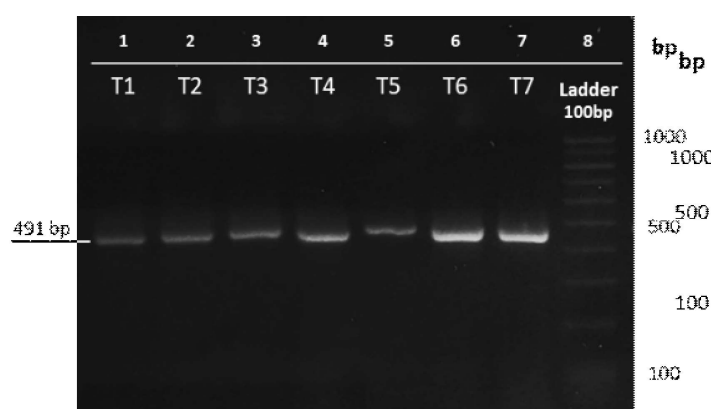

(a)

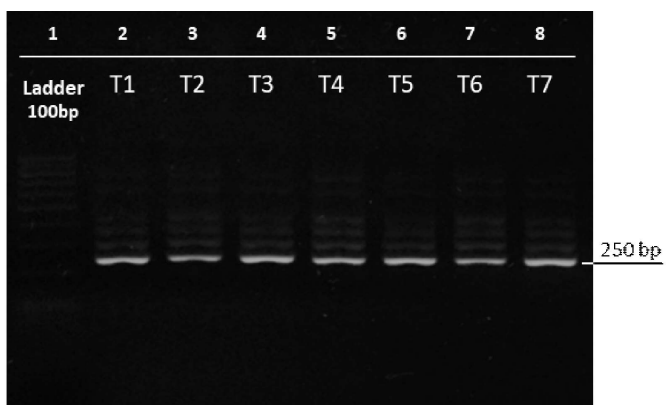

(b)

Figura 1. RT-PCR anidada para el segmento 3 del genoma del virus de la tilapia de lago (TiLV). Resultados de electroforesis de siete muestras positivas denominadas T1-T7. (a) Producto de PCR de $491 \mathrm{pb}$ de longitud en la primera ronda de PCRM; (b) bandas de 250 $\mathrm{pb}$ de longitud en PCR anidada

\section{Resultados}

\section{RT-PCR Anidada del Segmento 3 del TiLV}

Los resultados observados del RT-PCR anidada mostraron la amplificación de bandas de las muestras positivas analizadas. En la primera PCR (externa), se observó la presencia de una banda específica de $491 \mathrm{pb}$ (Figura 1a) correspondiente al segmento 3 del genoma de TiLV. Todos los productos de PCR de la primera ronda, se analizaron luego por PCR anidada, observándose que las muestras positivas amplificaron un producto de $251 \mathrm{pb}$ (Figura 1b).

Para confirmar los resultados, se secuenciaron los productos de $491 \mathrm{pb}$ obtenidos de siete cepas de campo denominados como T1 a T7.

\section{PCR del Segmento 4 y Secuencia}

La evaluación de los productos de la amplificación del segmento 4 del TiLV mostró bandas intensas de los tamaños esperados correspondientes a las porciones del seg- mento 4 , de 724 y 686 pb, respectivamente en las cinco muestras positivas (Figura 2). Por lo tanto, se enviaron las 10 secuencias amplificadas para la secuenciación bidireccional posterior.

\section{Alineamiento Múltiple y Análisis Filogenético}

Las secuencias completas fueron empalmadas y alineadas entre ellas, definiendo una longitud de $1190 \mathrm{pb}$. Fueron comparadas con cepas referenciales correspondiente al segmento 4 de TILV publicadas en el GeneBank. Se construyó un árbol filogenético (Figura 3) basado en la alineación de siete secuencias del segmento 4 de TiLV, las cuatro secuencias generadas en el presente estudio y tres secuencias de cepas disponibles en GeneBank que se seleccionaron como cepas de referencia (Cuadro 4). Se retiró del estudio a la muestra TILV Perú T07 por obtenerse secuencias incompletas (Cuadro 1).

Basado en el análisis filogenético en el segmento 4 , fue posible determinar la presencia de un genogrupo TiLV en el entorno local. El análisis filogenético indicó que las muestras locales presentan mayor relación 


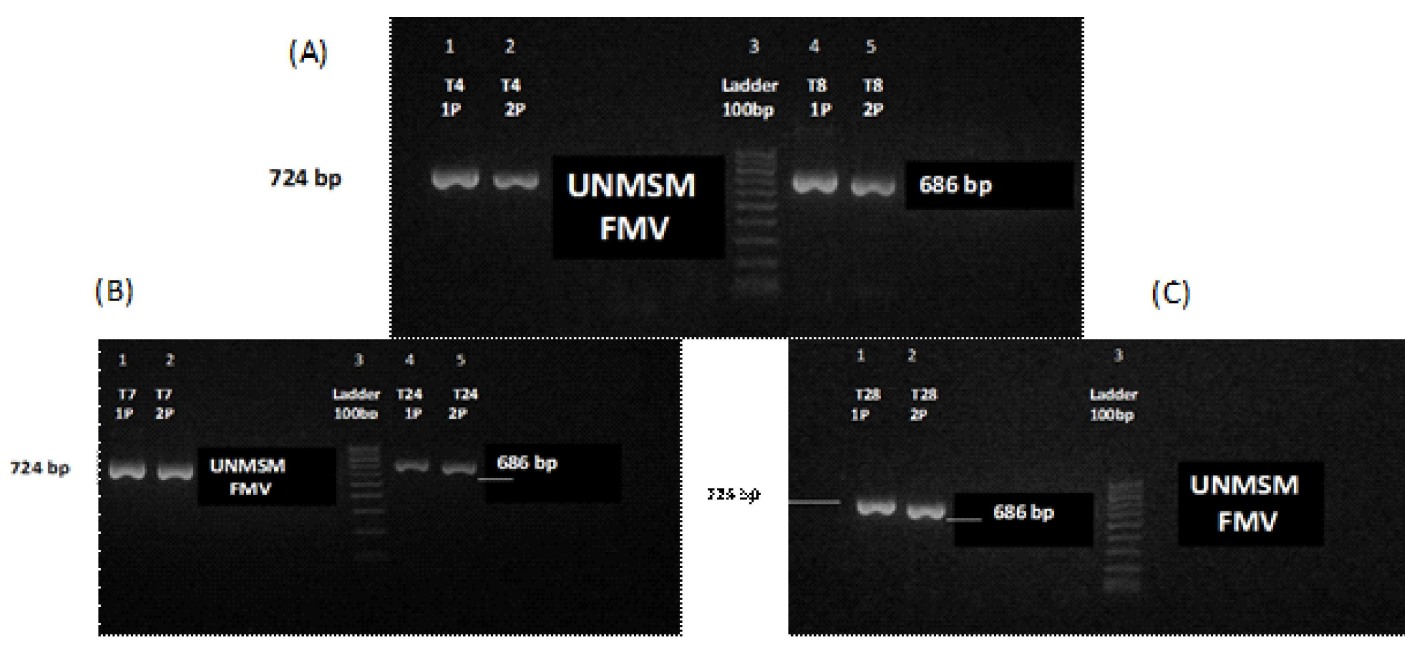

Figura 2. Electroforesis de los productos de la prueba de RT-PCR para el secuenciamiento del segmento 4 del virus de la tilapia de lago (TiLV). (A) Se observaron bandas de $724 \mathrm{pb}$ (carril 1 y carril 4) y $686 \mathrm{pb}$ (carril 2 y carril 5) de las muestras T4 y T8, respectivamente. (B) Se observaron bandas de $724 \mathrm{pb}$ (carril 1 y carril 4) y $686 \mathrm{pb}$ (carril 2 y carril 5) de las muestras T7 y T24, respectivamente. (C) Se observaron bandas de $724 \mathrm{pb}$ (carril 1) y $686 \mathrm{pb}$ (carril 2) de la muestra T28

genética con el clado de las cepas de Israel. El análisis de distancia genética muestra que las cuatro muestras peruanas mostraron valores de identidad de $99.7-100 \%$ entre ellas y 97.5-97.7\% con las cepas de Israel y 97.0$97.1 \%$ con las cepas de Tailandia.

\section{Análisis de Estructura y Función de la Proteína Hipotética}

En el modelamiento de las proteínas hipotéticas del TiLV usando Phyre2, la proteína hipotética del segmento 4 tiene un dominio en la región carboxilo (c1w21D) con una homología estructural con la cadena $\mathrm{D}$ de neuraminidasa N6 del pato inglés con una identidad de $44 \%$, una cobertura de $12 \%$ y una confianza de $25.2 \%$ (Figura 4). Se observa que esta región contiene un dominio conservado entre las secuencias de aminoácidos del segmento 4 con estructura de la familia sialidasas o neuraminidasas $(10.2 \%$ identidad), la neuraminidasa N1 (9.1\% identidad) y N2 (9.0\% identidad) del Influenza virus A.
Cuadro 4. Secuencias del segmento 4 del del virus de la tilapia de lago (TiLV) depositado en Gene Bank

\begin{tabular}{|c|c|c|}
\hline Origen & $\begin{array}{c}\mathrm{N}^{\circ} \mathrm{de} \\
\text { acceso al } \\
\text { GeneBank }\end{array}$ & Den \\
\hline Israel & KU751817.1 & $\begin{array}{l}\text { Til-4-2011 } \\
\text { segment } 4\end{array}$ \\
\hline Israel & KU552133.1 & $\begin{array}{l}\text { TiLV AD-2016 } \\
\text { contig } 5\end{array}$ \\
\hline Tailandia & KX631924.1 & $\begin{array}{l}\text { TiLV TV1 } \\
\text { segment } 4\end{array}$ \\
\hline
\end{tabular}

El análisis para determinar la presencia de regiones transmembrana por el software «TMpred prediction output», indica que existen dos hélices transmembrana (1803 de score) en la región de los animoácidos 245263 sentido interno-externo y 273-298 sentido externo-interno con un score de $790 \mathrm{y}$ 


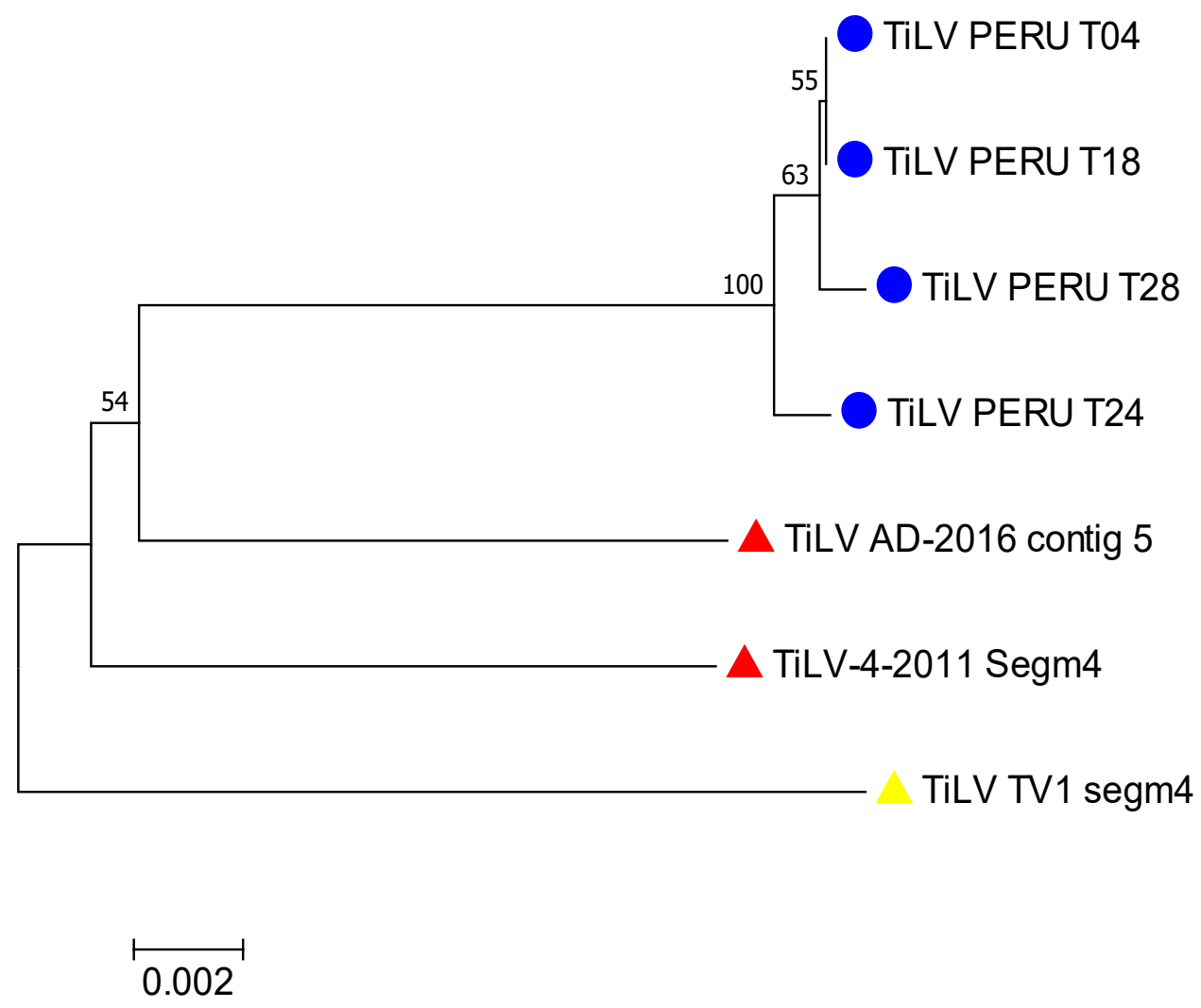

Figura 3. Análisis filogenético de la secuencia de nucleótidos del segmento 4 del virus de la tilapia de lago (TiLV) de Perú (círculos azules) y secuencias de referencia de Israel (rojo) y Tailandia (amarillo). Método de Neighbor-Joining, Bootstrap de 1000 réplicas, método de Kimura de 2 parámetros. Software MEGA v7.0.26

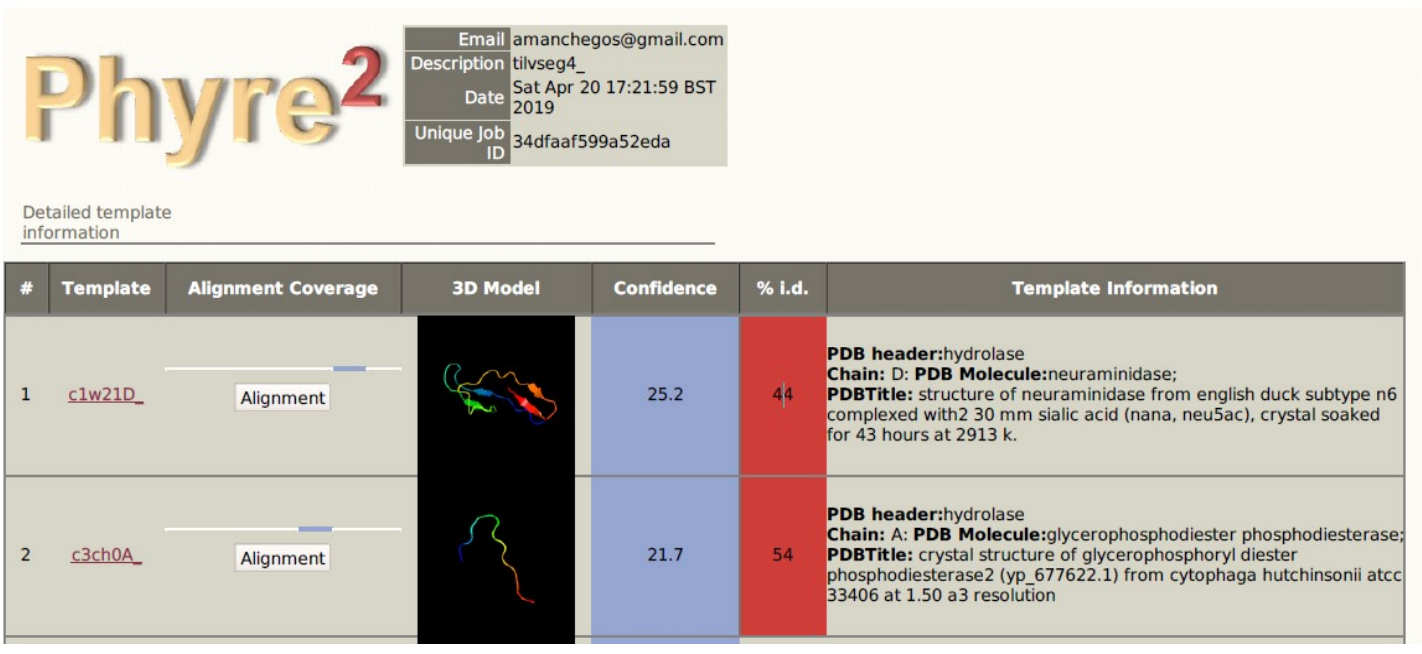

Figura 4. Reporte del programa Phyre2 del segmento 4 de TILV, determinando su similitud a la neuromimidasa 


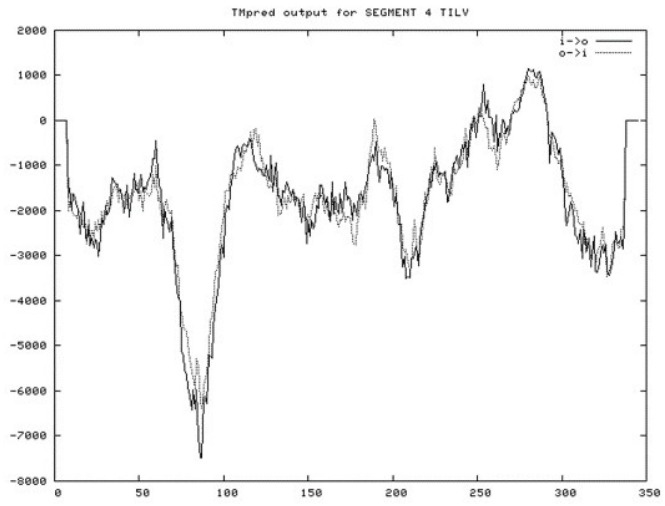

Figura 5. TMpred output para el segmento 4 de TILV. TMPRED.10087.8194.seq

1013, respectivamente (Figura 5), que indica que es una proteína con una ubicación transmembrana.

\section{Discusión}

No se dispone de estudios relacionados con la caracterización molecular de los segmentos del virus TiLV ni con la determinación de su posible función de la secuencia de la proteína hipotética obtenida. Este virus se ha descrito recientemente a nivel mundial, siendo causante de altas mortalidades de tilapias de cultivo y silvestres.

En el presente estudio se logró la caracterización molecular del segmento 4 del TiLV detectado en el Perú a partir de muestras positivas a TiLV provenientes de tilapias de cultivo de San Martín y Piura, obtenidas durante el brote registrado en 2017-2018. Basado en el análisis filogenético del segmento 4 , fue posible determinar la presencia de un genogrupo TiLV local (identidad de nucleótidos de 99.7-100\% entre ellas). Estas fueron las primeras notificaciones de mortalidades inusuales en Piura y meses después en San Martín (OIE, 2018b). El desplazamiento del virus en el territorio nacional podría explicarse por la venta frecuente de reproductores y alevines entre los departamentos con mayor producción, así como a través de movimientos informales de alevines y tilapias de ambientes naturales (embalses, lagos) con fines comerciales, aunado a la falta de aplicación de las buenas prácticas de acuicultura, limpieza, desinfección y bioseguridad en los centros de cultivo. Los resultados muestran un alto potencial de diseminación del virus, que puede causar grandes pérdidas a la industria acuícola, además de poner en riesgo la transmisión de la enfermedad a los peces silvestres (Abdullah et al., 2018).

Las secuencias obtenidas del segmento 4 del TiLV fueron empalmadas y alineadas entre ellas, definiendo una longitud de 1190 $\mathrm{pb}$ y fueron comparadas con cepas referenciales correspondiente al segmento 4 de TILV publicadas en Gene bank (Cuadro 5). La muestra TILV Perú T07 que presentó secuencias incompletas y que fue retirada del estudio, podría haberse debido a un exceso de ADN, presencia de sales o contaminantes en la muestra. El análisis filogenético determinó que las muestras presentan mayor relación genética con el clado de cepas de Israel; asimismo, el análisis de distancia genética evidencia que las muestras tienen valores de identidad de 97.5-97.7\% con cepas de Israel y $97.0-97.1 \%$ con cepas de Tailandia. La cercanía filogenética de las cepas locales con las de Israel podría indicar que provienen de un mismo origen. Es importante indicar que los primeros informes de mortalidad inusual de tilapias cultivadas y silvestres se registraron en Israel y tomó muchos años identificar el agente causal de esta enfermedad, tiempo en el que se pudo propagar la enfermedad debido al comercio de esta especie (Dong et al., 2017; Behera et al., 2018, Mugimba et al., 2018).

A pesar de que no se hizo la comparación con la cepa disponible de Ecuador (1065 pb) por ser de menor tamaño, se conoce que existe similitud entre dichas cepas con las cepas de Israel (Bacharach et al., 2016; Tsofack et al., 2017), de allí que es probable 
que la cepa de Ecuador también sea similar a la cepa peruana del TiLV y tengan el mismo origen.

A través de un análisis estructural de la proteína hipotética obtenida a partir de la secuencia del segmento 4 del TiLV, se determinó que un dominio situado en la región carboxilo tiene una homología estructural con la proteína neuraminidasa N6 del pato inglés y con la estructura básica de la familia sialidasas, donde sobresalen las Neurominasas de los Orthomixovirus como el virus de la Influenza (Wagner et al., 2002). El análisis bioinformático de las secuencias del segmento también determina la posible presencia de regiones transmembranas que indican que la proteína está ubicada en la cubierta del virus, dando mayores indicios que la proteína codificada en el segmento 4 del TILV es la neurominidasa viral.

Se ha descrito el uso de las proteínas de la cápside viral HA y NA como antígenos contra el Isavirus y el Influenzavirus (Mikalsen et al., 2005, Caruffo et al., 2016). Por lo cual, la posible función que desempeñaría este segmento 4 del TiLV como NA de acuerdo con los resultados, sería de vital importancia para la replicación del virus al participar en la liberación de los viriones de las células infectadas al exterior, mediante la ruptura de azúcares que ligan a las partículas virales maduras (Koren y Nylund 1997; Cheville y Lehmkuh, 2009). Además, la NA tiene beneficio adicional como antígeno de la vacuna, ya que muchos anticuerpos específicos de NA se unen a dominios que están bien conservados dentro de un subtipo, protegiendo contra virus heterólogos, lo que sugiere que la NA puede ser una buena opción para su inclusión en las vacunas universales contra Ortomixovirus (Eichelberger et al., 2018). Ante esto, es oportuno continuar con los estudios de la caracterización molecular del virus TiLV, en especial en los segmentos que codifican las proteínas inmunogénicas, con la finalidad de obtener un método de prevención, a través de la elaboración de una vacuna que contengan estas variantes génicas que las hagan inmunológicamente eficientes.

\section{Conclusiones}

- Se logró obtener cuatro secuencias del segmento 4 del TiLV con una longitud de $1190 \mathrm{pb}$.

- El análisis filogenético de las cuatro muestras peruanas determinó la presencia de un genogrupo TiLV local.

- Las muestras peruanas presentaron una mayor relación genética con el clado de cepas de Israel.

- La proteína hipotética a partir del segmento 4 del TiLV tuvo una homología estructural con las proteínas de la familia neuraminidasa y con las neurominidasas del virus de la influenza A.

\section{Agradecimientos}

Se agradece al Vicerrectorado de Investigación y Posgrado de la Universidad Nacional Mayor de San Marcos por el financiamiento del estudio.

\section{Literatura Citada}

1. Abdullah A, Ramly R, Syafiq $M$, Ridzwan M, Sudirwan F, Abas A, Ahmad K, et al. 2018. First detection of tilapia lake virus (TiLV) in wild river carp (Barbonymus schwanenfeldii) at Timah Tasoh Lake, Malaysia. J Fish Dis 41: 1459-1462. doi: 10.1111/jfd.12843

2. Adams M, Lefkowitz E, King A, Harrach B, Harrison R, Knowles $N$, Kropinski A, et al. 2017. Changes to taxonomy and the international code of virus classification and nomenclature ratified by the International Committee on Taxonomy of Viruses (2017). Arch Virol 162: 2505-2538. doi: 10.1007/ s00705-017-3358-5

3. Amal M, Koh C, Nurliyana $\mathrm{M}, \mathrm{Su}$ haiba M, Nor Amalina Z, Santha, Diyana-Nadhirah K. 2018. A case of natural co infection of tilapia lake virus and Aeromonas veronii in a Malaysian 
red hybrid tilapia (Oreoc-hromis niloticus x O. mossambicus) farm experiencing high mortality. Aquaculture 485: 12-16. doi: 10.1016/j.aquaculture.2017.11.019

4. Bacharach E, Mishra N, Briese T, Zody MC, Kembou Tsofack JE, Zamostiano R, et al. 2016. Characterization of a novel orthomyxo-like virus causing mass die-offs of Tilapia. MBio 7: e00431-16. doi: 10.1128/ mBio.00431-16

5. Behera B, Pradhan P, Swaminathan T, Sood N, Paria P, Das A, Verma D, et al. 2018. Emergence of tilapia lake virus associated with mortalities of farmed Nile tilapia Oreochromis niloticus (Linnaeus 1758) in India. Aquaculture: 168-174. doi: 10.1016/ j.aquaculture.2017.11.025

6. Caruffo M, Maturana C, Kambalapally S, Larenas J, Tobar J. 2016. Protective oral vaccination against infectious salmon anaemia virus in $\mathrm{Sal}$ mo salar. Fish Shellfish Immun 54: 5459. doi: 10.1016/j.fsi.2016.03.009

7. Clewley JP, Arnold C. 1997. MEGALIGN. The multiple alignment module of LASERGENE. Methods Mol Biol 70: 119-129.

8. Cheville N, Lehmkuh H. 2009. Orthomyxoviruses. In: Cheville NF (ed). Ultrastructural Pathology. $2^{\text {nd }} e d$. Ames, IA, USA: Wiley-Blackwell. p 356-357.

9. Del-Pozo J, Mishra N, Kabuusu R, Cheetham S, Eldar A, Bacharach E, Ferguson HW. 2017. Syncytial hepatitis of tilapia (Oreochromis niloticus L) is associated with orthomyxovirus-like virions in hepatocytes. Vet Pathol 54: 164-170. doi: $10.1177 / 0300985816658100$

10. Dong HT, Siriroob S, Meemetta W, Santimanawong $W$, Gangnonngiw $W$, Pirarat N, Senapin S. 2017. Emergence of tilapia lake virus in Thailand and an alternative semi-nested RT-PCR for detection. Aquaculture 476: 111-118. doi: 10.1016/j.aquaculture.-2017.04.019
11. Eichelberger C, Morens D, Taubenberger J. 2018. Neuraminidase as an influenza vaccine antigen: a low hanging fruit, ready for picking to improve vaccine effectiveness. Curr Opin Immunol 53: 38-44. doi: 10.1016/ j.coi.2018.03.025

12. Eyngor M, Zamostiano R, Kembou Tsofack JE, Berkowitz A, Bercovier H, Tinman S, Eldar A. 2014. Identification of a novel RNA virus lethal to tilapia. J Clin Microbiol 52: 4137-4146. doi: 10.1128/JCM.00827-14

13. [FAO] Food and Agriculture Organization of the United Nations. 2018. The state of world fisheries and aquaculture. Rome: FAO. 227 p.

14. Ferguson H, Kabuusu R, Beltran S, Reyes E, Lince J, del Pozo J. 2014. Syncytial hepatitis of farmed tilapia, Oreochromis niloticus (L): a case report. J Fish Dis 37: 583-589. doi: $10.1111 /$ jfd. 12142

15. Hofmann K, Stoffel W. 1993. TMBASE. A database of membrane spanning protein segments. Biol Chem Hoppe-Seyler 374: 166.

16. Jansen M, Dong H, Mohan C. 2018. Tilapia lake virus: a threat to the global tilapia industry? Rev Aquacult 11: 725739. doi: 10.1111 /raq. 12254

17. Kelley L, Mezulis S, Yates C, Wass M, Sternberg M. 2015. The Phyre2 web portal for protein modeling, prediction and analysis. Nat Protoc 10: 845. doi: 10.1038/nprot.2015.053

18. Koren C, Nylund A. 1997. Morphology and morphogenesis of infectious salmon anaemia virus replicating in the endothelium of Atlantic salmon Salmo salar. Dis Aquat Organ 29: 99-109. doi: 10.3354/dao029099

19. Kimura M. 1980. A simple model for estimating evolutionary rates of base substitutions through comparative studies of nucleotide sequences. J Mol Evol 16: 111-120. doi: 10.1007/bf01731581 
20. Kumar S, Stecher G, Tamura K.2016. MEGA7: Molecular Evolutionary Genetics Analysis version 7.0 for bigger datasets. Mol Biol Evol 33: 1870-1874. doi: 10.1093/molbev/msw054

21. Mikalsen AB, Sindre H, Torgersen J, Rimstad E. 2005. Protective effects of a DNA vaccine expressing the infectious salmon anemia virus hemagglutininesterase in Atlantic salmon. Vaccine 23: 4895-4905. doi: 10.1016/j.vaccine.2005.05.025

22. Mugimba K, Chengula A, Wamala $S$, Mwega E, Kasanga J, Byarugaba K, Mdegela R, et al. 2018. Detection of tilapia lake virus (TiLV) infection by PCR in farmed and wild Nile tilapia (Oreochromis niloticus) from Lake Victoria. J Fish Dis 41: 1181-1189. doi: $10.1111 /$ jfd. 12790 .

23. [OIE] World Organisation for Animal Health. 2018a. Tilapia lake virus (TiLV) - A novel orthomyxo-like virus. Aquatic Animal Health Code. [Internet] Available in: https://www.oie.int/fileadmin/Home/ eng/Internationa_Standard_Setting/docs/ pdf/A_TiLV_disease_card.pdf

24. [OIE] World Organisation for Animal Health. 2018b. Tilapia Lake Virus, Peru. Immediate Notification. [Internet] Available in: http://www.oie.int/wahis_2/ public/wahid.php/Reviewreport/ Review?page_refer $=$ MapFullEventReport\&reportid $=26027$

25. [PRODUCE] Ministerio de la Producción. 2017. Anuario estadístico pesquero y acuícola 2017. [Internet]. Disponible en: http://ogeiee.produce.gob.pe/ index.php/shortcode/oee-documentospublicaciones/publicaciones-anuales/ item/825-anuario-estadistico-pesquero$\mathrm{y}$-acuicola-2017

26. Plarre H, Nylund A, Karlsen M, Brevik Ø, Sæther PA, Vike S. Evolution of infectious salmon anaemia virus (ISA virus). Arch Virol 157: 2309-2326. doi: 10.1007/s00705-012-1438-0

27. Saito N, Nei M. 1987. The neighborjoining method: A new method for reconstructing phylogenetic tree. Mol Biol Evol 4: 406-425. doi: 10.1093/ oxfordjournals.molbev.a040454

28. [SANIPES] Organismo Nacional de Sanidad Pesquera del Perú. 2018. Presencia de Virus de la Tilapia Lacustre (TiLV) en el Perú. Comunicado $\mathrm{N}^{\circ}$ 018 -2018-SANIPES. [Internet]. Disponible en: https://www.sanipes.gob.pe/documentos/CCOMUNICADO-N-0182018-SANIPES.pdf

29. Surachetpong W, Janetanakit T, Nonthabenjawan $N$, Tattiyapong $P$, Sirikanchana $K$, Amonsin $A$. Outbreaks of tilapia lake virus infection, Thailand, 2015-2016. Emerg Infect Dis 23: 1031-1033. doi: 10.3201/ eid2306.161278

30. Thompson J, Higgins D, Gibson T. 1994. CLUSTAL W: improving the sensitivity of the progressive multiple sequence alignment through sequence weighting, position specific gap penalties and weight matrix choice. Nucleic Acids Res 22: 4673-4680. doi:10.1007/978-14020-6754-9_3188

31. Tsofack JE, Zamostiano R, Watted S, Berkowitz A, Rosenbluth E, Mishra N, Bacharach E. 2017. Detection of tilapia lake virus in clinical samples by culturing and nested reverse transcription PCR. J Clin Microbiol 55: 759-767. doi: 10.1128/JCM.01808-16

32. Wagner R, Feldmann A, Wol T, Pleschka S, Garten W, Klenk H. 2002. The role of hemagglutinin and neuraminidase in influenza virus pathogenicity. In: Holzenburg A, Bogner E (eds). Structure-function relationships of human pathogenic viruses. Boston, MA, USA: Springer. p 331-345. 